\title{
Detecting Attitudinal Changes about Death and Dying as a Result of End-of-Life Care Curricula for Medical Undergraduates
}

\author{
CAROLYN E. SCHWARTZ, SC.D., ${ }^{1-4}$ DAVID M. CLIVE, M.D., ${ }^{5}$ \\ KATHLEEN M. MAZOR, Ed.D., ${ }^{6}$ YUNSHENG MA, M.P.H., Ph.D., ${ }^{3}$ \\ GEORGE REED, Ph.D., ${ }^{3}$ and MARJORIE CLAY, Ph.D. ${ }^{7}$
}

\begin{abstract}
Background: There is heightened emphasis on teaching end-of-life (EOL) care in the medical school curriculum, but a relative paucity of tools focused on assessing key attitudinal changes due to curricula.

Objective: We sought to evaluate the responsiveness of two validated measures of relevant attitudes to changes caused by two EOL curricula: a year-long Elective and a day-long InterClerkship for medical undergraduates.

Design: A case control design $(n=100)$ and a one group pretest-posttest design $(n=98)$ were used to ask: (1) Are these two attitudinal measures responsive to changes induced by two undergraduate EOL curricula? (2) Do these two curricula have an additive effect (i.e., taking both yields a stronger attitudinal change than taking only one)? (3) Are there attitudinal and sociodemographic differences between students who took the year-long elective EOL course and those who did not?

Subjects: Undergraduate medical students.

Measurements: Two self-report measures: Concept of a Good Death and Concerns about Dying.

Results: Compared to nonelective participants, Elective participants reported less concern about working with dying patients at the end of the course and increased their valuation of clinical criteria in thinking about a "good death." There were trends suggesting decreased general concern about dying and increased valuation of closure, and an interaction suggesting a larger impact on those with higher precourse concern scores. There were no differences between elective and nonelective participants at baseline. The Interclerkship increased students' valuation of personal control aspects of death, and there was a trend in reducing con-

\footnotetext{
${ }^{1}$ QualityMetric Incorporated, Waltham, Massachusetts.

${ }^{2}$ Health Assessment Lab, Waltham, Massachusetts.

${ }^{3}$ Division of Palliative Medicine, Department of Medicine, University of Massachusetts Medical School, Worcester,

${ }^{4}$ DeltaQuest Foundation, Inc., Concord, Massachusetts.

${ }^{5}$ Division of Renal Medicine, Department of Medicine, University of Massachusetts Medical School, Worcester,

${ }^{6}$ Meyers Primary Care Institute, University of Massachusetts Medical School and Fallon Foundation, Worcester,

${ }^{7}$ Office of Ethics, University of Massachusetts Medical School, Worcester, Massachusetts.
} Massachusetts. Massachusetts. Massachusetts.
\end{abstract}


cerns about working with dying patients. We did not find an additive effect of taking both curricula.

Conclusions: We conclude that both measures were responsive to the relatively large effects this study would have been able to detect, and may be useful in future research to substantiate the effectiveness of EOL curricula in influencing attitudes and level of comfort with death and dying.

\section{INTRODUCTION}

A MONG THE MOST NOTABLE recent developments in American medical education is the recognition that end-of-life (EOL) care deserves a place in the medical school curriculum. Between 1975 and 2000, course offerings in death and dying increased in U.S. medical schools (from $7 \%$ to $18 \%$ of school surveyed), and more schools offered courses teaching a multidisciplinary team approach (from $59 \%$ to $78 \%$ ). ${ }^{1}$ In 2000 , palliative care was directly addressed in $87 \%$ of U.S. medical schools, and students had direct exposure to a hospice patient, ${ }^{1}$ an intervention that can greatly enhance students' and spiritual awareness and enable them to care more effectively for people who are dying. ${ }^{2}$ Nonetheless, an international survey of undergraduate medical education in palliative medicine revealed that as of 2000, rotations in undergraduate palliative medicine education were lacking in Canadian, U.S., and Western European medical schools, and that the majority of medical schools had only one faculty member in palliative medicine. ${ }^{3}$ Furthermore, postgraduate specialty training programs in the United States suffer from a lack of comprehensive EOL training requirements across programs. ${ }^{4}$ Although ethics and psychosocial care are frequently mandated, training in pain assessment and management as well as EOL communication and other more personal aspects of care were mandated in very few specialties. ${ }^{4}$ It is thus not surprising that medical students and residents report feeling unprepared to provide many key components of good care for the dying. ${ }^{5-7}$ This feeling of being unprepared is substantiated by the deficiencies documented in the patterns of care provided to dying patients by current practitioners. ${ }^{6,8-12}$ Consequently, many of those committed to improving EOL care have called for changes in both undergraduate and graduate medical education programs so that future practitioners will be better prepared to care for dying patients..$^{8,13}$
This call has been answered by a wave of EOL care curricula aimed at undergraduate ${ }^{14-16}$ and graduate $^{4,17}$ medical students. To enhance the consistency across programs, the Association of American Medical Colleges (AAMC) developed curricular objectives in EOL care that focus on improving seven cognitive, affective, and behavioral dimensions relevant to providing comprehensive and compassionate care. ${ }^{18}$

However, the evaluation component of such programs has been lacking in clarity and cohesiveness. Many evaluations that have been implemented have lacked a control group (i.e., a group of students who have not received an educational intervention). Additionally, the cognitive and behavioral evaluation approaches that have become standard for other aspects of medical education (e.g., competency-based testing via oral examination, direct observation, or sophisticated multiple-choice examinations; structured essays; or objective structured clinical examinations) are still in development. ${ }^{19}$ Many published evaluation studies rely on student self-reported knowledge or confidence in delivering key components of good EOL care ${ }^{20-22}$ or on faculty's global ratings of such proficiency. ${ }^{23}$

Another hindrance to EOL curriculum evaluation relates to the quality and standards of measures of attitudinal constructs that are at least as important to delivering quality EOL care as their cognitive and behavioral counterparts, but may present more of a challenge to evaluate effectively. Attitudinal constructs have been assessed in a small number of EOL curriculum evaluation studies, and have focused on perceived value of ${ }^{24}$ or comfort with ${ }^{25}$ the course, or attitudes towards hospice, ${ }^{26,27}$ or the perspective of various stakeholders in the hospital community (e.g., learners, attending physicians, nursing staff) toward the curriculum. ${ }^{28}$ These attitudinal constructs have usually been assessed by single questions, which are likely to be less reliable than multi-item scales, or focus group interviews, an approach that can be valuable for hypothesis generation but less so 
in demonstrating the impact of an educational intervention on broadly recognized and valued outcomes of EOL curriculum. One study used validated tools but was unable to document an effect on attitudinal change as a result of an EOL curriculum. ${ }^{29}$

Attitudinal barriers to quality EOL care are substantial,, 10 but there is a growing consensus that these barriers could be overcome with appropriate educational intervention. ${ }^{30-32}$ There is a need for psychometrically sound tools that address and are responsive to changes in key aspects of the attitudinal barriers to and enablers of good EOL care. ${ }^{19,33}$ Responsiveness is a distinct characteristic of validation that requires longitudinal data comparing pre and postscores around an intervention presumed to have an impact on the constructs measured by the tools. The present work thus sought to ask three questions: (1) Are these two attitudinal measures responsive to changes induced by two undergraduate EOL curricula? (2) Do these two curricula have an additive effect (i.e., taking both yields a stronger attitudinal change than taking only one)? (3) Are there attitudinal and sociodemographic differences between students who took the year-long elective EOL course and those who did not? We used two measures that were specifically developed to assess attitudes and values that are intimately related to EOL care: concept of a good death and concerns about dying. Both tools were constructed using language that is understandable and acceptable to both lay people and medical professionals, and experienced and inexperienced palliative care providers. Thus, while initially validated for use in healthcare providers in training, they would be amenable for use in a variety of patient and other lay samples for whom assessing these attitudes would be helpful. The validation of both tools was done in a previous study by our group that included four cohorts $(n=596)$ : medical students, graduate students in biology, nursing students, and hospice nurses. The baseline data from the medical students included in the present study were part of the original validation study. ${ }^{34,35}$ This validation study demonstrated internal consistency, test-retest reliability, and construct validity, but did not address responsiveness. If the present study confirms the responsiveness of these measures to attitudinal changes caused by EOL curricula, then the tools may be useful in other institutions seeking standardized tools for evaluating such curricula.

\section{METHODS}

\section{Subjects and procedure}

Participants in this study were 100 first-year medical students (Class of 2004) and 98 third-year medical students (Class of 2002) at the University of Massachusetts Medical School. Class of 2004 students completed a brief questionnaire as part of a larger data collection effort implemented by the Office of Medical Education. These data were collected in the fall and spring of the participants' first year of medical school, corresponding to just before and just after the year-long elective course. The questionnaire was also administered to 98 third-year medical students (Class of 2002) before and after participating in the day-long Interclerkship on EOL care, during the spring of the students' third year.

\section{Measures}

Two measures were used in the present work. The Concept of a Good Death measure ${ }^{34}$ consists of 17 descriptive statements of the various components that might be considered important to one's concept of a good death. The measure builds on Walden-Galuszko and coworkers' 36,37 concepts of a "traditional" versus "modern" death, and includes dimensions that are increasingly recognized as important at the end of life, including spiritual peace, acceptance, closure with family and friends, pain, etc. The individual items were gleaned from discussions with clinicians as well as the published lay and professional literature. ${ }^{36-41}$ The item pool was reduced in further discussions with our own research team to eliminate redundant items. The measure assesses three domains (closure, personal control, clinical criteria). Items are rated on a 4-point Likert scale ranging from "not necessary" to "essential." In previous work done by our group, these scales demonstrated good item frequency distributions, acceptable internal consistency reliability ( $\alpha=0.75,0.83,0.62$, respectively), and moderately high stability over a 14-day retest period $\left(\mathrm{ICC}=0.66,0.83\right.$, and 0.70). ${ }^{34}$ Subscale scores are item means and range from 1 to 4 . Based on prior work done by others, ${ }^{37}$ we would expect that medical students would generally would value clinical criteria more over the course of training. Given the specific focus of the elective course, we expect that elective participants would value closure more. 
The Concerns about Dying (CD) instrument ${ }^{35}$ consists of 10 descriptive statements intended to assess directly providers' comfort level in working with dying patients, as well as general concerns about death. The CD measures three distinct areas related to anxiety in dealing with death and/or dying patients: general concern about death, spirituality, and concerns about working with dying patients. The general subscale focuses on normal rather than pathological feelings and beliefs about death. The spirituality subscale addresses the importance of spiritual beliefs in thinking about death, and the belief in the continuance of the soul after death. The patient-related subscale assesses concerns about working with dying patients. CD items are statements followed by five response options: disagree completely, disagree somewhat, neutral, agree somewhat, and agree completely. Item scoring was done such that greater agreement reflected greater anxiety or concern about death or dying. Subscale scores were computed by taking the mean of the subscale's items, and range from 1 to 5 . In the validation study, test-retest reliability of these three scores was good $(r=0.84,0.89,0.83$, respectively), internal consistency was adequate $(\alpha=0.73,0.76,0.85$, respectively), and correlations with related measures and between-group differences supported its construct and discriminant validity. Because the intent of the EOL curricula was to help students feel more comfortable and prepared to deal with dying patients, we would expect that students who participated in the elective would show significant decreases on the general and patient-related subscales, but no change on the spirituality subscale since medical education does not address spirituality.

Participants also provided demographic and educational information, such as age, intended specialty, and ethnicity. Appendix A contains copies of both measures.

\section{The educational intervention}

At the University of Massachusetts Medical School, two educational curricula for teaching EOL care have been developed. The first is an elective course known as Caring for the Seriously Ill (referred to as elective henceforth). The second method for teaching EOL care is an "interclerkship course," a 1-day experience given to thirdyear medical students between two of their clerk- ships (i.e., approximately two thirds of the way through the third year).

The Caring for the Seriously Ill Elective Course. The objectives of this course are (1) to familiarize students with the principles of EOL care; (2) to increase the comfort level of students in approaching incurably ill and terminal patients; (3) to stimulate students to explore their own attitudes about death. The Elective course is taught in seven evening sessions between the months of November and April. Approximately 50 first- and second-year students are enrolled on a first-come, first-served basis. The course is now in its eighth year.

The course has three components. Each session begins with an interactive 1-hour whole-group exercise that may be in the format of a lecture, panel discussion, or interview. The presenters are faculty, patients, patients' family members, or health care professionals. The topics of these presentations are, in order, The Dying Experience, Breaking Bad News, Spirituality in End-of-Life Care, Childhood Death and Dying, Advance Directives, Hospice and Palliative Care Medicine, and Bereavement.

Immediately after each large-group exercise, students and faculty break into small discussion groups that meet for the next hour. Each group comprises 6 to 8 students and two preceptors, of whom one is a physician, and the other a nonphysician professional. Typically, groups reflect on the material that has just been presented in the whole-group session. The content of these discussions tends to be more personal.

The third component of the elective is a series of encounters that students have with seriously or terminally ill patients. The patients are recruited from physician practices and the hospice program affiliated with the UMass Memorial Health Care system. Typical diagnoses include neoplastic diseases, end-stage emphysema, congestive heart failure, and neurodegenerative diseases. Each patient is assigned to a student or pair of students, who meet with the patient periodically for the duration of the course, at the patient's convenience. The meetings may take place in the patient's home, in a clinic space, or in hospice. It is not unusual for a patient to die prior to the end of the course. These encounters provide the substance for much of the small-group discussion. At the end of the course, students are required to write a short paper reflecting on their experiences 
with their assigned patient or some other aspect of death and dying covered in the course.

The interclerkship. The goals of the single-day Interclerkship are similar to those of the elective course, although it is more clinical and practical in focus. The morning is devoted to whole-group events: an interview with a terminally ill patient; an interactive case discussion encompassing many aspects of EOL care; and a skill demonstration of how to break bad news to patients. During the afternoon, five 1-hour workshops are offered. Each student attends two workshops. A mandatory workshop addresses symptom management in terminally ill patients. Students may choose their second workshop from among the other four, the topics of which include Limitation of Treatment ("Comfort Measures Only" and "Do Not Resuscitate" orders), Spirituality in EOL Care, Practical Aspects (What to do when a Patient Dies); and Childhood EOL Care.

\section{Statistical analysis}

$T$ tests and Fisher's exact tests (for continuous and categorical variables, respectively) were used to compare students who opted to take the Elective with those who did not in the class of 2004. Mean scores of Concept of a Good Death and Concerns about Dying domains and the changes over time were calculated for each group. Change scores were calculated as follow-up minus baseline, and two-group $t$ tests were used to compare means between students who took the elective and those that did not. In addition, linear regression analyses were estimated in which Concept of a Good Death and Concerns about Dying change scores were predicted by participant characteristics (e.g., baseline subscale score, age, gender, and ethnicity).

For the Class of 2002, Concept of a Good Death and Concerns about Dying change scores (preinterclerkship and postinterclerkship) were calculated, and a one-sample $t$ test was used to test whether the mean changes were significantly different from zero. The effect on change scores of taking the Elective course after the Interclerkship was tested by: (1) using a $t$ test to compare group mean change scores; (2) using linear regression analysis to evaluate the effect of taking the Elective course on change scores after adjusting for pre-Interclerkship scores as well as possible confounders. In this model, change score was the dependent variable, and Elective (yes/no) and baseline score, age, gender and ethnicity were the independent variables. The association of the change score and baseline score was the same in each group, and results are consistent with a repeated-measures analysis of variance (ANOVA) analytic approach. Effect sizes were computed based on the adjusted difference in change divided by the pooled standard deviation of change in score.

\section{RESULTS}

\section{Subjects}

The sample comprised 198 students with a mean age of 28.4 years (standard deviation $[S D]=3.7)$ for Class of 2002 and 26.7 years $(S D=$ 4.3) for Class of 2004. Table 1 presents baseline characteristics of the samples as well as $t$ statistics and $p$ value comparing the two groups' scores at baseline to determine if there were any differences between the samples prior to the educational intervention that might have confounded our results. There were none, as indicated by the nonsignificant $p$ values. Students were predominantly Caucasian, with approximately equal numbers of males and females. A diverse range of specialty intentions were listed, with the modal category being "undecided" for students who did not take the elective, and "pediatric medicine" for those who did take the Elective course. There were, however, no statistical differences in baseline sociodemographic or attitudinal characteristics between students who opted to take the elective and those who did not (Table 1).

\section{Impact of elective}

Thirty-six students from the Class of 2004 chose to take the elective, of whom 31 provided complete data for analysis. Of the 64 not taking the course, 62 provided complete data for analysis. Students who took the elective had similar preelective scores to those that did not, suggesting that there was no selection bias contaminating our findings (Table 1). Elective participants reported less concern about working with dying patients at the end of the course (2.84 versus 3.18 , adjusted change score -0.45 $[-0.72,-0.18], p<0.001)$, and there was a trend suggesting a decrease in general concern, compared to nonelective students at posttest after adjusting for baseline scores and demo- 
Table 1. Baseline Characteristics ${ }^{\mathrm{a}}$

\begin{tabular}{|c|c|c|c|c|}
\hline & \multirow[b]{2}{*}{$\begin{array}{l}\text { Class of } 2002 \\
(\mathrm{n}=98)\end{array}$} & \multicolumn{3}{|c|}{$\begin{array}{l}\text { Class of } 2004 \\
n=53\end{array}$} \\
\hline & & $\begin{array}{c}\text { Took elective } \\
(\mathrm{n}=36) \\
\text { Mean }(S D) \text { or } \mathrm{n}(\%)\end{array}$ & $\begin{array}{c}\text { Did not take } \\
\text { elective }(\mathrm{n}=64) \\
\text { Mean }(S D) \text { or } \mathrm{n}(\%)\end{array}$ & $\begin{array}{l}\mathrm{p} \text { value } \mathrm{b} \\
(\mathrm{t} \text { statistic })\end{array}$ \\
\hline Age: mean (sd) & $28.37(3.65)$ & $27.18(5.13)$ & $26.45(3.81)$ & $0.45(-0.75)$ \\
\hline $\begin{array}{l}\text { Gender: No. }(\%) \\
\text { Male } \\
\text { Female }\end{array}$ & $\begin{array}{l}47(50.54) \\
46(49.46)\end{array}$ & $\begin{array}{l}16(44.44) \\
20(55.56)\end{array}$ & $\begin{array}{l}33(51.56) \\
31(48.44)\end{array}$ & $0.49(0.47)$ \\
\hline $\begin{array}{l}\text { Race/ethnicity: No. (\%) } \\
\text { White } \\
\text { Others }\end{array}$ & $\begin{array}{l}75(80.65) \\
18(19.35)\end{array}$ & $\begin{array}{r}30(83.33) \\
6(16.67)\end{array}$ & $\begin{array}{l}52(81.25) \\
12(18.75)\end{array}$ & 1.0 \\
\hline $\begin{array}{l}\text { Religion: No. (\%) } \\
\text { Catholic } \\
\text { Jewish } \\
\text { Agnostic } \\
\text { Protestant, Methodist, Christian } \\
\text { Eastern Religion } \\
\text { Other } \\
\text { None }\end{array}$ & $\begin{aligned} 15 & (16.30) \\
14 & (15.22) \\
3 & (3.26) \\
17 & (18.48) \\
5 & (5.43) \\
4 & (4.35) \\
34 & (36.96)\end{aligned}$ & $\begin{aligned} 11 & (30.56) \\
2 & (5.56) \\
0 & (0) \\
10 & (27.78) \\
5 & (13.89) \\
0 & (0) \\
8 & (22.22)\end{aligned}$ & $\begin{aligned} 27 & (42.19) \\
3 & (4.69) \\
3 & (4.69) \\
10 & (15.63) \\
4 & (6.25) \\
6 & (9.38) \\
11 & (17.19)\end{aligned}$ & 0.15 \\
\hline $\begin{array}{l}\text { Specialty: No. }(\%) \\
\text { Family Medicine } \\
\text { Pediatric Medicine } \\
\text { Emergency Medicine } \\
\text { Internal Medicine } \\
\text { Surgery } \\
\text { Other } \\
\geq 1 \text { concentration } \\
\text { Unknown }\end{array}$ & $\begin{aligned} 12 & (13.04) \\
21 & (22.83) \\
7 & (7.61) \\
13 & (14.14) \\
4 & (4.35) \\
12 & (13.04) \\
16 & (17.39)\end{aligned}$ & $\begin{aligned} 6 & (16.67) \\
10 & (27.78) \\
1 & (2.78) \\
9 & (25.00) \\
1 & (2.78) \\
2 & (5.56) \\
3 & (8.33) \\
4 & (11.11)\end{aligned}$ & $\begin{aligned} 13 & (20.31) \\
8 & (12.50) \\
6 & (9.38) \\
10 & (15.63) \\
3 & (4.69) \\
3 & (4.69) \\
4 & (6.25) \\
17 & (26.56)\end{aligned}$ & 0.27 \\
\hline \multicolumn{5}{|l|}{ Concerns about Dying: Mean (SD) } \\
\hline $\begin{array}{l}\text { General } \\
\text { Spiritual } \\
\text { Patient-Related }\end{array}$ & $\begin{array}{l}3.50(0.75) \\
2.68(1.07) \\
2.83(0.88)\end{array}$ & $\begin{array}{l}3.50(0.77) \\
2.44(0.93) \\
3.40(0.86)\end{array}$ & $\begin{array}{l}3.36(0.82) \\
2.21(1.14) \\
3.29(0.81)\end{array}$ & $\begin{array}{l}0.40(-0.84) \\
0.30(-1.11) \\
0.54(-0.62)\end{array}$ \\
\hline \multicolumn{5}{|l|}{ Concept of a Good Death: Mean (SD) } \\
\hline $\begin{array}{l}\text { Personal control } \\
\text { Closure } \\
\text { Clinical Criteria }\end{array}$ & $\begin{array}{l}1.98(0.56) \\
3.03(0.40) \\
2.12(0.49)\end{array}$ & $\begin{array}{l}2.31(0.54) \\
2.93(0.42) \\
2.01(0.48)\end{array}$ & $\begin{array}{l}2.12(0.54) \\
2.82(0.38) \\
2.02(0.43)\end{array}$ & $\begin{array}{l}0.11(-1.61) \\
0.18(-1.35) \\
0.94(0.07)\end{array}$ \\
\hline
\end{tabular}

aAll students released their data for inclusion so the samples reflect the whole class, not a subset.

$\mathrm{b}_{p}$ values are from $t$ test for two-group means or Fisher's exact test for categorical variables between students taking the elective or not in the Class of 2004.

$\mathrm{SD}$, standard deviation.

graphic characteristics (3.40 versus 3.51 , adjusted change score $-0.17[-0.35,0.02], p<$ $0.10)$. The course also appeared to influence elective participants' concept of a good death, leading to an increased valuation of clinical criteria $(2.06$ versus 1.89 , adjusted change score $0.16[0.01,0.31], p<0.05)$ and a trend suggesting that they valued closure more (3.01 versus 2.82 , adjusted change score $0.15[-0.03,0.33]$, $p<0.10){ }^{a}{ }^{a}$ These findings were generally consistent with our hypotheses, but the $p$ values were not as significant as hypothesized, particularly if one were to adjust for multiple com- parisons. ${ }^{42}$ This conservative approach would only consider $p$ values of less than 0.008 to be statistically significant. Effect sizes of change

\footnotetext{
${ }^{a}$ We chose to present $t$ tests followed by regression analysis of the adjusted change score because we felt that it was a logical approach that would be familiar and comfortable with the clinical audience anticipated for this journal. Alternatively, we could have presented a repeated-measures ANOVA with interaction terms to examine differences between those medical students who did the elective vs. those who did not, adjusting for demographic differences. We have implemented both analytic approaches and found they yield the same conclusions.
} 
scores revealed moderate effects for changes in concerns about dying, closure, and clinical criteria, and large effects for changes in patientrelated concerns (Fig. 1). Changes in spiritual concerns and personal control were not clinically important (Table 2).

There was a significant interaction $(p=0.002)$ of taking the elective course with prescores for patient-related concerns about death, after adjusting for baseline values. The course had a larger impact on those with higher precourse Concerns about Dying scores. Figure 2 illustrates this relationship, showing the steeper slope for the elective group versus the nonelective group when comparing change in score to precourse scores.

\section{Impact of interclerkship}

Of the 98 students, 10 had missing Concept of a Good Death and Concerns about Dying scores for either the pre- or postmeasure. The 1-day interclerkship appeared to have an impact on students' valuation of personal control aspects of death (mean change $=0.21, \mathrm{SD}=0.50, t=3.84$, $p<0.0002$ ), and there was a trend suggesting that students' patient-related concerns about death also decreased over the course of the day (mean change $=-0.15, \mathrm{SD}=0.68, t=-1.96$, $p=0.054)$. There were no statistically significant changes in spiritual beliefs or general concerns about death, or in the valuation of closure or clinical EOL care. We also looked for a possible additive effect by examining the interaction of the Interclerkship with taking the elective by comparing change in subscale scores between the 37 students who took the elective and the 51 who did not for whom we had complete data. Mean changes in scores were similar for the elective participants and the nonelective participants with regard to Concerns about Dying and Concept of a Good Death ( $p$ values $>0.3$ for all comparisons, data not shown).

\section{DISCUSSION}

We found that both measures were responsive to attitudinal changes among students in the elec-

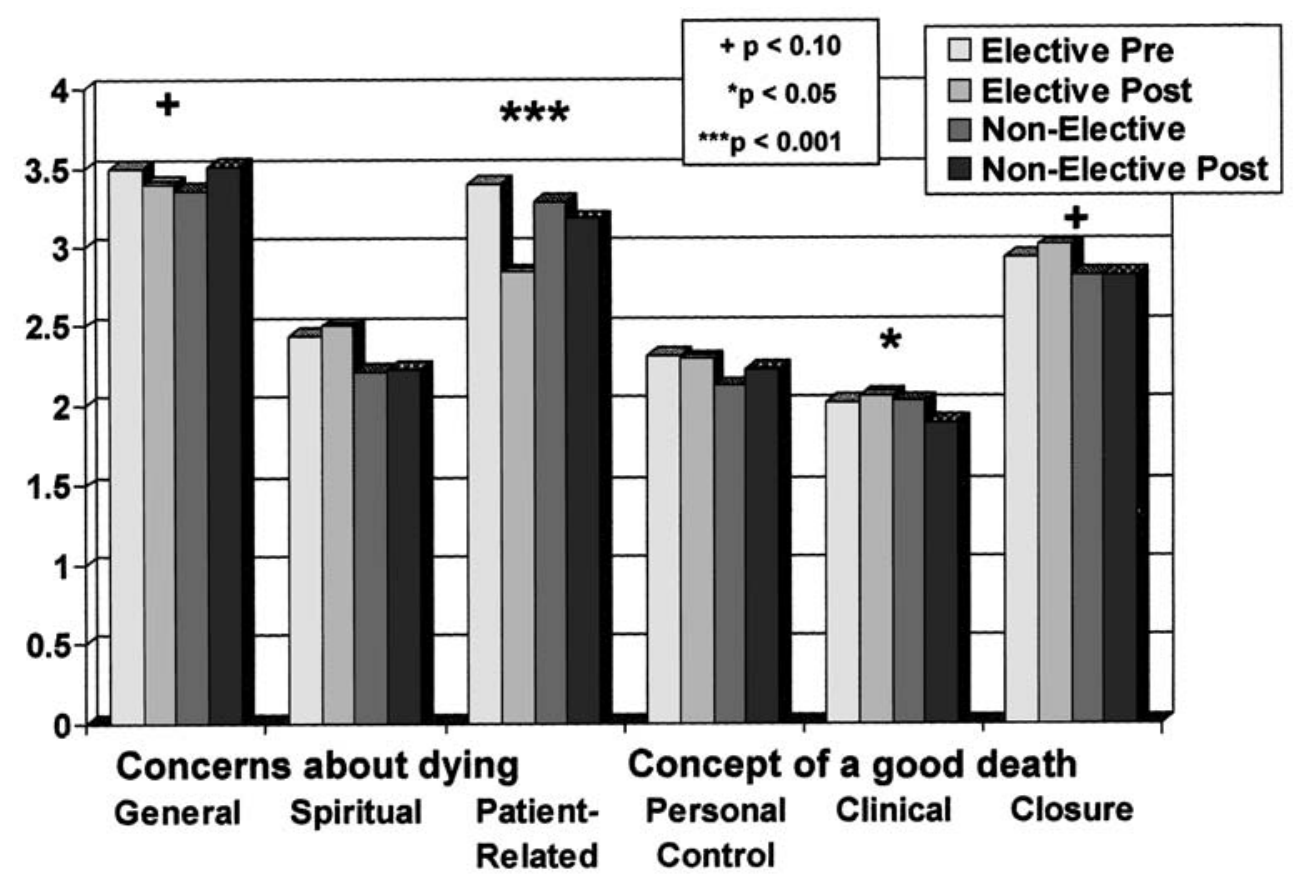

FIG. 1. Bar graph depicting the elective course's impact on Class of 2004 students' concerns about dying and concept of a good death. Students who participated in the elective reported less concern about working with dying patients at the end of the course $(p<0.001)$ and there was a trend suggesting a decrease in general concern $(p<0.10)$, compared to nonelective students at posttest and after adjusting for baseline scores. The course also appeared to influence participants' concept of a good death, leading to an increased valuation of clinical criteria $(p<0.05)$ and a trend suggesting that they valued closure more $(p<0.10)$. 
Table 2. Elective Course's Impact on Students' Concerns About Dying and Concept of a Good Death in Class of 2004

\begin{tabular}{|c|c|c|c|c|}
\hline Variable & No elective & Elective & $\mathrm{p}$ value & $\begin{array}{c}\text { Effect } \\
\text { size }\end{array}$ \\
\hline Concerns about Dying & Mean (SD) & Mean (SD) & & \\
\hline \multicolumn{5}{|l|}{ General } \\
\hline Pre & $3.36(0.82)$ & $3.50(0.77)$ & 0.403 & \\
\hline Post & $3.51(0.76)$ & $3.40(0.63)$ & 0.472 & \\
\hline Unadjusted change & $0.13(0.49)$ & $-0.07(0.50)$ & 0.072 & \\
\hline Adjusted change ${ }^{a}$ & \multicolumn{2}{|c|}{$-0.17[-0.35,0.02]$} & 0.084 & 0.34 \\
\hline \multicolumn{5}{|l|}{ Spiritual } \\
\hline Pre & $2.21(1.14)$ & $2.44(0.93)$ & 0.296 & \\
\hline Post & $2.23(1.04)$ & $2.50(1.11)$ & 0.255 & \\
\hline Unadjusted change & $0.06(0.58)$ & $0.03(0.55)$ & 0.828 & \\
\hline Adjusted change $\mathrm{a}^{\mathrm{a}}$ & \multicolumn{2}{|c|}{$0.01[-0.23,0.25]$} & 0.919 & 0.02 \\
\hline \multicolumn{5}{|l|}{ Patient Related } \\
\hline Pre & $3.29(0.81)$ & $3.40(0.86)$ & 0.535 & \\
\hline Post & $3.18(0.77)$ & $2.84(0.70)$ & 0.042 & \\
\hline Unadjusted change & $-0.09(0.57)$ & $-0.62(0.96)$ & 0.001 & \\
\hline Adjusted change $\mathrm{e}^{\mathrm{a}}$ & \multicolumn{2}{|c|}{$-0.45[-0.72,-0.18]$} & 0.001 & 0.58 \\
\hline \multicolumn{5}{|l|}{ Concept of a Good Death } \\
\hline \multicolumn{5}{|l|}{ Personal control } \\
\hline Pre & $2.12(0.54)$ & $2.31(0.54)$ & 0.114 & \\
\hline Post & $2.23(0.61)$ & $2.29(0.55)$ & 0.628 & \\
\hline Unadjusted change & $0.13(0.53)$ & $-0.01(0.65)$ & 0.272 & \\
\hline Adjusted change ${ }^{\mathrm{a}}$ & \multicolumn{2}{|c|}{$-0.05[-0.28,0.18]$} & 0.656 & 0.08 \\
\hline \multicolumn{5}{|l|}{ Clinical criteria } \\
\hline Pre & $2.02(0.42)$ & $2.01(0.48)$ & 0.942 & \\
\hline Post & $1.89(0.41)$ & $2.06(0.45)$ & 0.067 & \\
\hline Unadjusted change & $-0.13(0.37)$ & $0.03(0.46)$ & 0.074 & \\
\hline Adjusted change $\mathrm{a}^{\mathrm{a}}$ & \multicolumn{2}{|c|}{$0.16[0.01,0.31]$} & 0.040 & 0.39 \\
\hline \multicolumn{5}{|l|}{ Closure } \\
\hline Pre & $2.82(0.38)$ & $2.93(0.42)$ & 0.181 & \\
\hline Post & $2.82(0.46)$ & $3.01(0.42)$ & 0.057 & \\
\hline Unadjusted change & $-0.03(0.47)$ & $0.07(0.43)$ & 0.314 & \\
\hline Adjusted change ${ }^{\mathrm{a}}$ & \multicolumn{2}{|c|}{$0.15[-0.03,0.33]$} & 0.094 & 0.33 \\
\hline
\end{tabular}

aBaseline-adjusted change score from regression analysis, where change score was the dependent variable and elective (yes/no) and baseline score were the independent variables. Confidence Intervals for the difference are in brackets.

$\mathrm{SD}$, standard deviation.

tive and the interclerkship. Even after adjusting for multiple comparisons, we found that students who participated in the elective reported less concern about working with dying patients, and there were trends suggested less general concern about dying, increased valuation of closure, and increased valuation of clinical criteria. The course had a larger impact on those with higher precourse concern scores, and showed clinically significant effects on changes in concerns about dying, closure, clinical criteria, and patient-related concerns. The Interclerkship appeared to lead to an increased valuation of personal control aspects of death and there was a trend suggesting a reduction in students' concerns about working with dying patients. We did not find an additive effect of taking both the elective and the interclerkship.

Our results substantiate the effectiveness of both a year-long elective and a 1-day interclerkship in influencing students' attitudes and beliefs about death and dying, and in increasing their reported level of comfort in working with seriously ill patients. We believe that the implications of our findings for EOL curriculum in other schools are that either a year-long elective or a brief 1day Inter-clerkship can be effective in altering students' level of concern about working with dying patients, but appear to lead to distinct concepts of a good death. The longer curriculum seems to affect the value student placed on more psychosocial and existential concerns (i.e., closure), whereas the shorter curriculum appeared 


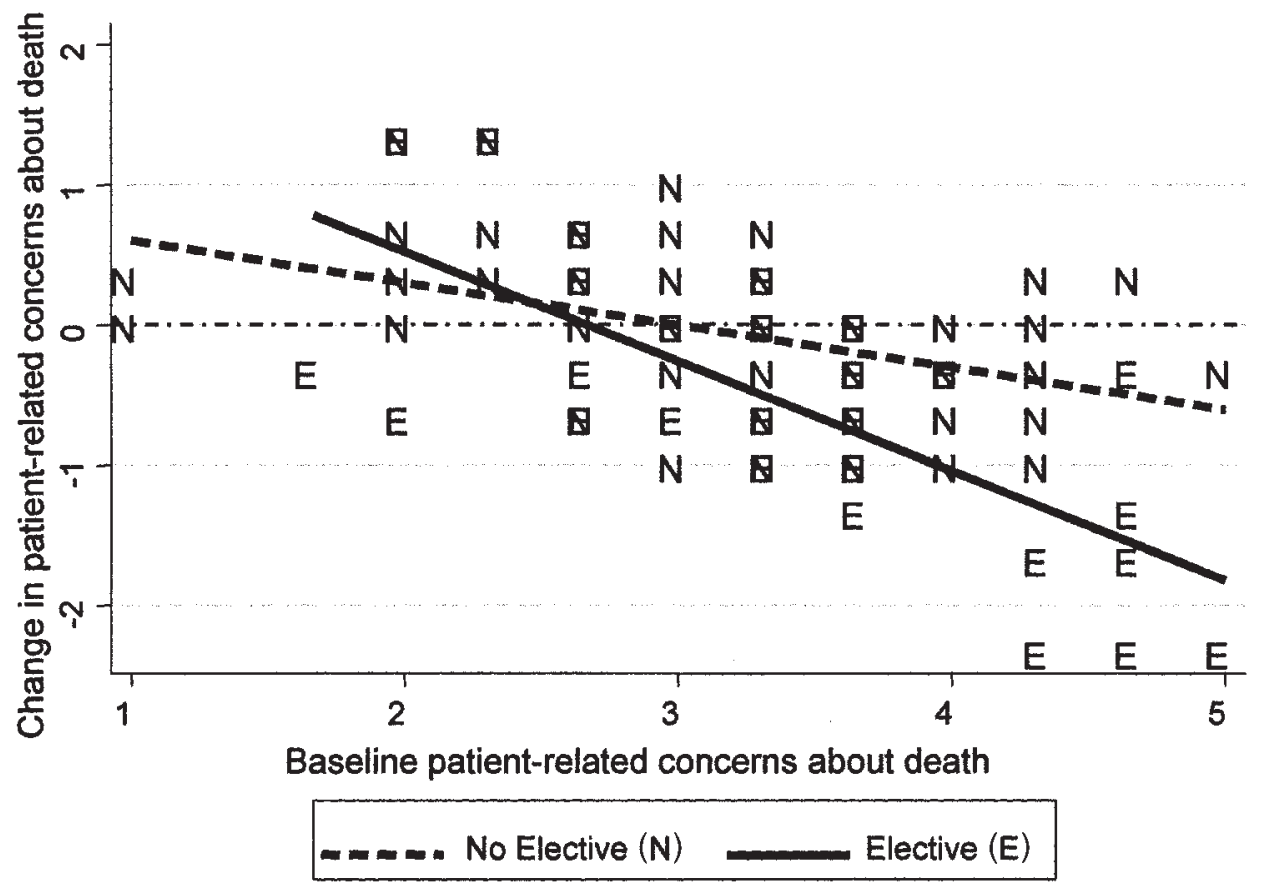

FIG. 2. The course had a larger impact in reducing patient-related concerns on those with higher precourse concern scores. There was a steeper slope for the elective group versus the nonelective group comparing change in score to precourse scores $(p=0.002)$.

to affect the importance of patients' control over bodily function. These different priorities may reflect perceived emphases of the overall curriculum, or may reflect the impact of the personal contact and experience the students had with their dying patient partner in the year-long elective. Future research might utilize these tools to explore in greater detail how variations in EOL curriculum across medical schools are associated with different patterns of value changes regarding concept of a good death, or changes in levels of general, spiritual, or patient-related concerns about dying.

Our results suggest that use of these nonparticipants for comparison is valid (i.e., there were no systematic biases between students who opted to participate in the elective compared to those who did not), and provides useful information about the impact of the elective over time. The limitations of the present work should, however, be noted. First, the impact of the two curricula was compared in one group of students, not in successive cohorts. It is possible that an additive effect of the two curricula would be more detectable with several cohorts followed over time. Second, the sample sizes of the elective cohorts was relatively small, allowing one to detect rela- tively large differences and not the more subtle differences that may have a substantial cumulative effect over the many years of training. Third, the temporal proximity to the Interclerkship of pretesting and posttesting may have overpowered our ability to demonstrate that students who took the elective responded any differently to the Interclerkship. Finally, our study did not address the impact of these curricula on subsequent postgraduate choices (e.g., residency program selections) or on differences in attitude within residency programs among people given such training, as compared to those who were not. In short, there are a number of questions that the present study was not designed to address but that are highly relevant for understanding the impact of an undergraduate EOL curriculum on medical providers.

Dealing with dying patients is generally considered to be one of the greatest challenges that clinicians face. The educational interventions described herein were aimed at mitigating the barriers to effective EOL care by forcing students to explore their own feelings about death and to understand the skills necessary for treating the dying. While some may feel it ill-advised to confront fledgling medical students with such a difficult 
agenda, ${ }^{6,9}$ the present work demonstrates that such interventions can engender positive effects. It is our hope that by validating these tools and demonstrating their responsiveness to attitudinal change, other EOL investigators will utilize them in deeper explorations of EOL curriculum at both the undergraduate and graduate levels.

\section{ACKNOWLEDGMENTS}

This work was supported in part by the Macy Initiative in Health Communication at the University of Massachusetts Medical School. We would also like to acknowledge Laura Sefton for assistance with data collection, Lorna Chiasson and Katharine Gendreau for data management support, Blandyna Williams for assistance in manuscript preparation, and Anastasia Raczek, M.Ed., for helpful comments on earlier manuscript drafts.

\section{REFERENCES}

1. Dickinson GE: A quarter century of end-of-life issues in U.S. medical schools. Death Stud 2002;26:635-646.

2. MacLeod RD, Parkin C, Pullon S, Robertson G: Early clinical exposure to people who are dying: learning to care at the end of life. Med Educ 2003;37:51-58.

3. Oneschuk D, Hanson J, Bruera E: An international survey of undergraduate medical educationin palliative medicine. J Pain Symptom Manage 2000;20:174-179.

4. Weissman DE, Block SD: ACGME requirements for end-of-life training in selected residency and fellowship programs: A status report. Acad Med 2002;77: 299-304.

5. Sullivan AM, Lakoma MD, Block SD: The status of medical education in end-of-life care: a national report. J Gen Intern Med 2003;18:685-695.

6. Wear D: "Face-to-face with It": Medical students' narratives about their end-of-life education. Acad Med 2002;77:271-277.

7. Weissman DE, Ambuel B, Norton AJ, Wang-Cheng R, Schiedermayer D: A survey of competencies and concerns in end-of-like care for physician trainees. J Pain Symptom Manage 1998;15:82-90.

8. Whitcomb ME: Meeting the challenge to improve end-of-life-care education. Acad Med 2002;77:269270.

9. Field MJ, Cassel CK (eds): Educating clinicans and other professionals. In: Approaching Death: Improving Care at the End of Life Committee on Care at the End of Life. Washington, D.C.: National Academy Press, 1997, pp. 207-234.
10. Bradley EH, Cramer LD, Bogardus ST Jr, Kasl SV, Johnson-Hurzeler R, Horwitz SM: Physicians' ratings of their knowledge, attitudes, and end-of-life-care practices. Acad Med 2002;77:305-311.

11. Ury WA, Berkman CS, Weber CM, Pignotti MG, Leipzig RM: Assessing medical students' training in end-of-life communication: A survey of interns at one urban teaching hospital. Acad Med 2003;78: 530-537.

12. Buss MK, Marx ES, Sulmasy DP: The preparedness of students to discuss end-of-life issues with patients. Acad Med 1998;73:418-422.

13. Teno JM, Fisher ES, Hamel MB, Coppola K, Dawson NV: Medical care inconsistent with patients' treatment goals: Association with 1-year Medicare resource use and survival. J Am Geriatr Soc 2002;50: 496-500.

14. Magnani JW, Minor MA, Aldrich JM: Care at the end of life: A novel curriculum module implemented by medical students. Acad Med 2002;77:292-298.

15. Fins JJ, Gentilesco BJ, Carver A, Lister P, Acres CA, Payne R, Storey-Johnson C: Reflective practice and palliative care education: A clerkship responds to the informal and hidden curricula. Acad Med 2003;78: 307-312.

16. Wood EB, Meekin SA, Fins JJ, Fleischman AR: Enhancing palliative care education in medical school curricula: Implementation of the palliative education assessment tool. Acad Med 2002;77:285-291.

17. Weissman DE, Mullan P, Ambuel B, von Gunten CF, Hallenbeck J, Warm E: End-of-life graduate education curriculum project. Project abstracts/progress reports-year 2. J Palliat Med 2001;4:525-547.

18. Block SD: Medical education in end-of-life care: the status of reform. J Palliat Med 2002;5:243-248.

19. Quill TE, Dannefer E, Markakis K, Epstein R, Greenlaw J, McGrail K, Milella M: An integrated biopsychosocial approach to palliative care training of medical students. J Palliat Med 2003;6: 365-380.

20. Linder JF, Blais J, Enders SR, Melberg SE, Meyers FJ: Palliative education: A didactic and experiental approach to teaching end-of-life care. J Cancer Educ 1999;14:154-160.

21. Ross DD, Fraser HC, Kutner JS: Institutionalization of a palliative and end-of-life care educational program in a medical school curriculum. J Palliat Med 2001;4: 512-518.

22. Meekin SA, Klein JE, Fleischman AR, Fins JJ: Development of a palliative education assessment tool for medical student education. Acad Med 2000;75:986992.

23. Mullan PB, Weissman DE, Ambuel B, von Gunten C: End-of-life care education in internal medicine residency programs: an interinstitutional study. J Palliat Med 2002;5:487-496.

24. Serwint JR, Rutherford LE, Hutton N, Rowe PC, Barker S, Adamo G: "I learned that no death is routine": Description of a death and bereavement semi- 
nar for pediatrics residents. Acad Med 2002;77:278284.

25. Lypson ML, Hauser JM: Talking medicine: A course in medical humanism-What do third-year medical students think? Acad Med 2002;77:1169-1170.

26. Lloyd-Williams M, Dogra N: Caring for dying patients-What are the attitudes of medical students? Support Care Cancer 2003;11:696-699.

27. Lloyd-Williams M, Dogra N: Attitudes of preclinical medical students towards caring for chronically ill and dying patients: Does palliative care teaching make a difference? Postgrad Med J 2004;80(939): 31-34.

28. Ury WA, Arnold RM, Tulsky JA: Palliative care curriculum development: A model for a content and process-based approach. J Palliat Med 2002;5:539-548.

29. Fischer SM, Gozansky WS, Kutner JS, Chomiak A, Kramer A: Palliative care education: An intervention to improve medical residents' knowledge and attitudes. J Palliat Med 2003;6:391-399.

30. Curtis JR, Patrick DL, Caldwell ES, Collier AC: Why don't patients and physicians talk about end-of-life care? Barriers to communication for patients with acquired immunodeficiency syndrome and their primary care clinicians. Arch Intern Med 2000;160:1690-1696.

31. Curtis JR, Patrick DL: Barriers to communication about end-of-life care in AIDS patients. J Gen Intern Med 1997;12:736-741.

32. Meier DE, Morrison RS, Cassel CK: Improving palliative care. Ann Intern Med 1997;127:225-230.

33. Morzinski JA, Montagnini ML: Logic modeling: A tool for improving educational programs. J Palliat Med 2002;5:566-570.

34. Schwartz CE, Mazor K, Rogers J, Ma Y, Reed G: Validation of a new measure of concept of a good death. J Palliat Med 2003;6:575-584.
35. Mazor K, Schwartz CE, Rogers JH: Development and testing of a new instrument for measuring concerns about dying in healthcare providers. Assessment 2004;11:230-237.

36. Walden-Galuszko KD, Majkowicz M, Trzebiatowska IA: A comparative study of the views of the medical staff, medical students and non-health professionals [Abstract]. Acta Oncol 1998;37.

37. Walden-Galuszko KD, Majkowicz M, Trzebiatowska IA: Pojêcie dobrej oemierci u peronelu medycznego. Psychoonkologia 1997;1:39-43.

38. Cohen LM, Poppel DM, Cohn GM, Reiter GS: A very good death: Measuring quality of dying in end-stage renal disease. J Palliat Med 2001;4:167-172.

39. Byock IR: Dying Well: The Prospect for Growth at the End of Life. New York: Riverhead Books, 1997.

40. Cohen LM, Germain MJ, Poppel DM, Woods AL, Pekow PS, Kjellstrand CM: Dying well after discontinuing the life-support treatment of dialysis. Arch Intern Med 2000;160:2513-2518.

41. Hinton J: The progress of awareness and acceptance of dying assessed in cancer patients and their caring relatives. Palliat Med 1999;13:19-35.

42. Miller RG: Simultaneous Statistical Inference, 2nd ed. New York: Springer-Verlag, 1981.

Address reprint requests to: Carolyn Schwartz, Sc.D. 31 Mitchell Road Concord, MA 01742

E-mail: carolyn.schwartz@deltaquest.org 
Appendix A. Measures Used

The Concept of a Good Death Measure

Please indicate how important is each of the following is to your conception of a "good" death.

\begin{tabular}{|c|c|c|c|c|}
\hline Subscale listed in parentheses & $\begin{array}{l}\text { Not } \\
\text { necessary }\end{array}$ & Desirable & Important & Essential \\
\hline 1. That it be painless or largely pain-free. (Clinical Criteria) & 1 & 2 & 3 & 4 \\
\hline 2. That the dying period be short. (Clinical Criteria) & 1 & 2 & 3 & 4 \\
\hline 3. That it be sudden and unexpected. (Clinical Criteria) & 1 & 2 & 3 & 4 \\
\hline 4. That family and doctors follow the person's wishes. (Closure) & 1 & 2 & 3 & 4 \\
\hline $\begin{array}{l}\text { 5. That it occur naturally, without technical equipment. } \\
\text { (Clinical Criteria) }\end{array}$ & 1 & 2 & 3 & 4 \\
\hline 6. That it be peaceful. (Closure) & 1 & 2 & 3 & 4 \\
\hline 7. That loved ones be present. (Closure) & 1 & 2 & 3 & 4 \\
\hline 8. That the person's spiritual needs be met. (Closure) & 1 & 2 & 3 & 4 \\
\hline 9. That the person is able to accept death. (Closure) & 1 & 2 & 3 & 4 \\
\hline $\begin{array}{l}\text { 10. That the person had a chance to complete important tasks. } \\
\text { (Closure) }\end{array}$ & 1 & 2 & 3 & 4 \\
\hline 11. That the person had an opportunity to say "good-bye." (Closure) & 1 & 2 & 3 & 4 \\
\hline 12. That the person was able to remain at home. (Closure) & 1 & 2 & 3 & 4 \\
\hline 13. That the person lived until a key event. (Closure) & 1 & 2 & 3 & 4 \\
\hline 14. That death occurs during sleep. (Clinical Criteria) & 1 & 2 & 3 & 4 \\
\hline 15. That there be mental alertness until the end. (Personal Control) & 1 & 2 & 3 & 4 \\
\hline $\begin{array}{l}\text { 16. That there be control of bodily functions until death. } \\
\text { (Personal Control) }\end{array}$ & 1 & 2 & 3 & 4 \\
\hline $\begin{array}{l}\text { 17. That the ability to communicate be present until death. } \\
\text { (Personal Control) }\end{array}$ & 1 & 2 & 3 & 4 \\
\hline
\end{tabular}

Concerns about Dying Measure

Please indicate the extent to which you agree or disagree with the following.

\begin{tabular}{|c|c|c|c|c|c|}
\hline Subscale listed in parentheses & $\begin{array}{l}\text { Disagree } \\
\text { completely }\end{array}$ & $\begin{array}{l}\text { Disagree } \\
\text { somewhat }\end{array}$ & Neutral & $\begin{array}{l}\text { Agree } \\
\text { somewhat }\end{array}$ & $\begin{array}{c}\text { Agree } \\
\text { completely }\end{array}$ \\
\hline $\begin{array}{l}\text { 1. I get anxious or uncomfortable when I think } \\
\text { about my own death. (General) }\end{array}$ & 1 & 2 & 3 & 4 & 5 \\
\hline $\begin{array}{l}\text { 2. I sometimes worry that I will die young. } \\
\text { (General) }\end{array}$ & 1 & 2 & 3 & 4 & 5 \\
\hline $\begin{array}{l}\text { 3. I believe that my soul or spirit will continue } \\
\text { after death. (Spiritual) }\end{array}$ & 1 & 2 & 3 & 4 & 5 \\
\hline $\begin{array}{l}\text { 4. I get anxious or uncomfortable when I think } \\
\text { about someone I care about dying. } \\
\text { (Patient-related) }\end{array}$ & 1 & 2 & 3 & 4 & 5 \\
\hline $\begin{array}{l}\text { 5. My religious and/or spiritual beliefs and } \\
\text { practices help me think about death. } \\
\text { (Spiritual) }\end{array}$ & 1 & 2 & 3 & 4 & 5 \\
\hline $\begin{array}{l}\text { 6. I'm worried that my own death may be } \\
\text { painful. (General) }\end{array}$ & 1 & 2 & 3 & 4 & 5 \\
\hline $\begin{array}{l}\text { 7. I think that when it's time for me to die, I will } \\
\text { be able to "let go." (General) }\end{array}$ & 1 & 2 & 3 & 4 & 5 \\
\hline $\begin{array}{l}\text { 8. I am worried about how I will react } \\
\text { emotionally to dying patients (Patient- } \\
\text { related). }\end{array}$ & 1 & 2 & 3 & 4 & 5 \\
\hline $\begin{array}{l}\text { 9. I think that I will feel powerless with dying } \\
\text { patients (Patient-related). }\end{array}$ & 1 & 2 & 3 & 4 & 5 \\
\hline $\begin{array}{l}\text { 10. I think I will find it hard to work with dying } \\
\text { patients (Patient-related). }\end{array}$ & 1 & 2 & 3 & 4 & 5 \\
\hline
\end{tabular}

